\title{
The Relationship between Birthweight and Longitudinal Changes of Blood Pressure Is Modulated by Beta-Adrenergic Receptor Genes: The Bogalusa Heart Study
}

\author{
Wei Chen, ${ }^{1}$ Sathanur R. Srinivasan, ${ }^{1}$ D. Michael Hallman, ${ }^{2}$ and Gerald S. Berensonn ${ }^{1}$ \\ ${ }^{1}$ Center for Cardiovascular Health, Department of Epidemiology, Tulane University Health Sciences Center, \\ New Orleans, LA 70112, USA \\ ${ }^{2}$ Human Genetics Center, University of Texas-Houston Health Science Center, Houston, TX 77030, USA
}

Correspondence should be addressed to Gerald S. Berenson, berenson@tulane.edu

Received 16 July 2009; Revised 21 December 2009; Accepted 25 February 2010

Academic Editor: Wenjiang J. Fu

Copyright ( $) 2010$ Wei Chen et al. This is an open access article distributed under the Creative Commons Attribution License, which permits unrestricted use, distribution, and reproduction in any medium, provided the original work is properly cited.

\begin{abstract}
This study examines the genetic influence of $\beta$-adrenergic receptor gene polymorphisms ( $\beta_{2}$-AR Arg16Gly and $\beta_{3}$-AR Trp64Arg) on the relationship of birthweight to longitudinal changes of blood pressure (BP) from childhood to adulthood in 224 black and 515 white adults, aged 21-47 years, enrolled in the Bogalusa Heart Study. Blacks showed significantly lower birthweight and frequencies of $\beta_{2}$-AR Gly16 and $\beta_{3}$-AR Trp64 alleles and higher BP levels and age-related trends than whites. In multivariable regression analyses using race-adjusted $\mathrm{BP}$ and birthweight, low birthweight was associated with greater increase in age-related trend of systolic BP (standardized regression coefficient $\beta=-0.09, P=.002)$ and diastolic $\mathrm{BP}(\beta=-0.07, P=.037)$ in the combined sample of blacks and whites, adjusting for the first BP measurement in childhood, sex, age, and gestational age. Adjustment for the current body mass index strengthened the birthweight-BP association. Importantly, the strength of the association, measured as regression coefficients, was modulated by the combination of $\beta_{2}$-AR and $\beta_{3}$-AR genotypes for systolic $(P=.042$ for interaction $)$ and diastolic BP age-related trend $(P=.039$ for interaction), with blacks and whites showing a similar trend in the interaction. These findings indicate that the intrauterine programming of BP regulation later in life depends on $\beta$-AR genotypes.
\end{abstract}

\section{Introduction}

Low birthweight is an indicator of intrauterine growth retardation. The relationship between low birthweight and elevated blood pressure (BP) levels later in life and the mechanisms of fetal programming have been extensively studied since the fetal origins hypothesis was proposed [14]. However, evidence for the developmental programming of adult hypertension thus far is still inconsistent, particularly in pediatric populations [5-7]. Recently, researchers have outlined substantive challenges to the birthweight$\mathrm{BP}$ association. One of the criticisms is the inappropriate use of statistical methodology and improper interpretation of epidemiologic analyses in support of the fetal origins hypothesis [3, 8-12].

$\beta$-adrenergic receptors ( $\beta$-ARs) play a pivotal role in regulation of cardiac, pulmonary, vascular, endocrine, and sympathetic nervous systems $[13,14]$. Three $\beta$-AR subtypes $\left(\beta_{1}-\mathrm{AR}, \beta_{2}-\mathrm{AR}\right.$, and $\left.\beta_{3}-\mathrm{AR}\right)$ are pharmaceutically characterized $[14,15]$. Polymorphisms of the $\beta$-AR genes have been found to be associated with multiple cardiovascular risk variables, including hemodynamic factors such as heart rate, vasodilation, and BP [16]. Further, the $\beta$-AR genes are associated with preterm birth and modulate the relationship between birthweight and insulin resistance in later life [1720]. However, whether genetic variations in the $\beta$-AR genes modulate the influence of birthweight on BP is not known, especially for BP longitudinal changes.

As part of the Bogalusa Heart Study, a long-term biracial (black-white) community-based epidemiologic study of the early natural history of cardiovascular disease beginning in childhood since 1973 [21], the present study examines the modulating effect of $\beta_{2}$-AR Arg16Gly and $\beta_{3}$-AR Trp64Arg polymorphisms on the association between birthweight and 
longitudinal changes of BP from childhood to adulthood in black and white asymptomatic younger adults enrolled in the Bogalusa Heart Study.

\section{Methods}

2.1. Study Cohort. In the community of Bogalusa, LA, 9 cross-sectional surveys of children aged 4-17 years between 1973 and 1994 and 10 cross-sectional surveys of young adults aged 18-48 years between 1987 and 2009, who had been previously examined as children, were conducted for cardiovascular risk factors. This panel design of repeated cross-sectional examinations conducted approximately every 3 years has resulted in serial observations from childhood to adulthood. A total of 739 adult subjects (515 whites and 224 blacks; $42.2 \%$ males; age range $=21-47$ years; mean age $=$ 36.7 years) who had $\beta$-AR gene polymorphism genotype data formed the study cohort for this report. The study subjects have been serially examined 4-14 times (at least 2 times each in childhood and adulthood) for BP over an average of 26.7 years, with 5793 observations. Birthweight records of the participants were obtained from the Office of Health Statistics in New Orleans, Louisiana. All subjects in this study gave informed consent at each examination, and for those under 18 years of age, consent of a parent/guardian was obtained. Study protocols were approved by the Institutional Review Board of the Tulane University Health Sciences Center.

2.2. General Examinations. All surveys since 1973 followed the same protocols, and procedures for the general examinations were described elsewhere [22]. Height and weight were measured twice to $\pm 0.1 \mathrm{~cm}$ and to $\pm 0.1 \mathrm{~kg}$, respectively. Body mass index (BMI, weight in kilograms divided by the square of the height in meters) was used as a measure of overall adiposity. BP levels were measured on the right arm of subjects in a relaxed, sitting position by 2 nurses ( 3 replicates each). The first and fourth Korotkoff phases were used to determine systolic (SBP) and diastolic (DBP) blood pressures, respectively. Means of replicate readings were used for analyses. For subjects $(n=57)$ who were on medications for hypertension at the time of examination, we adjusted the recorded BP levels by adding $10 \mathrm{~mm} \mathrm{Hg}$ to SBP and $5 \mathrm{~mm} \mathrm{Hg}$ to DBP, based on average treatment effects $[23,24]$.

2.3. Genotyping. Genotyping of $\beta_{2}$-AR Arg16Gly and $\beta_{3}-\mathrm{AR}$ Trp64Arg polymorphisms was performed using the TaqMan assay (Applied Biosystems, Inc., Foster, CA) in the laboratory of the Human Genetics Center, University of Texas School of Public Health, 1200 Hermann Pressler, E447, Houston. Amplification conditions and information on primer and probe sequences have been previously described $[25,26]$. The reproducibility of genotyping of the three polymorphisms was $100 \%$ assessed by 64 blind duplicates.

2.4. Statistical Methods. Cubic growth curves of BP measured repeatedly at multiple time points from childhood to adulthood were established by race and sex groups using a random effects model by SAS Proc MIXED. As shown in Figure 1 using SBP of two white males as an example, the area under the curve (AUC) was calculated as the integral of the growth curve parameters during the follow-up period for each individual $[27,28]$. Total AUC (baseline AUC + incremental AUC) is considered a measure of long-term levels. Incremental AUC determined by within-individual variability represents a combination of linear and nonlinear longitudinal trends and was used as the measure of agerelated trend. Since individuals had different follow-up periods, the AUC values were divided by the number of follow-up years for further analyses. The AUC measures have advantages over other longitudinal analysis models in that they measure both the long-term levels and trends.

Race differences in distributions of genotypes and allele frequencies were tested using a contingency chi-square test. Differences in mean values of continuous study variables between race-sex groups were tested by analysis of covariance models. The rate of fetal growth was calculated as birthweight in kilograms/gestational age in weeks for each individual, and then multiplied by the mean gestational age of the sample to make the scale close to the original values. The gestational age-adjusted birthweight was used in all subsequent analyses. The impact of genotype and birthweight on BP was examined by multiple regression models by race and in the total sample, adjusting for sex, current age, and race (for the total sample). In order to examine the impact of BMI adjustment on the relation between birthweight and BP, two types of regression analyses were performed, with and without adjustment for current BMI. In addition to the above covariates, the baseline BP (the first measurement in childhood) was also included in the regression models for the agerelated trend analyses to control for the regression-to-themean bias because the baseline values were closely associated with the age-related trend measured by incremental AUC. The differences in slopes (birthweight-genotype interaction on BP) were tested using a homogeneity-of-slopes model, a regression interaction model, among genotype groups. Due to significant differences in BP levels, birthweight and gene allele frequencies between blacks and whites, BP measures (childhood, adulthood, AUC, and age-related trend), and birthweight were standardized into $Z$-scores (mean $=0$ and $\mathrm{SD}=1$ ) by race groups prior to regression analyses to remove the influence of population stratification.

\section{Results}

Table 1 shows the mean levels of study variables in childhood, adulthood, and at birth, and AUC values by race and sex. The first measurement of childhood SBP and DBP did not significantly differ between races or sexes. The last measurement of adulthood SBP and DBP differed significantly by race (blacks $>$ whites) and by sex (males $>$ females) except for sex difference in blacks. Total AUC and age-related trend of SBP showed significant race (blacks > whites) and sex (males > females) differences; significant sex differences (males $>$ females) were noted for total DBP AUC in both races and a significant race difference (blacks $>$ whites) in females only. The age-related trend of DBP showed 


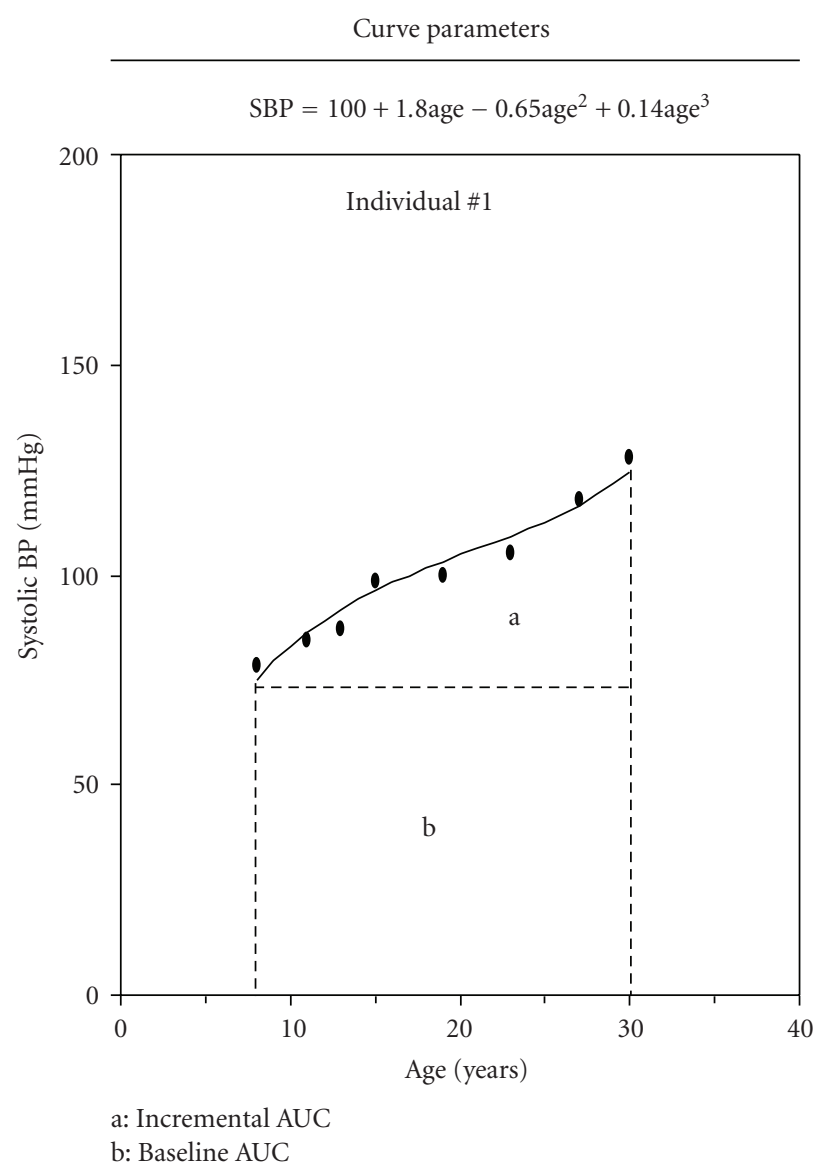

(a)

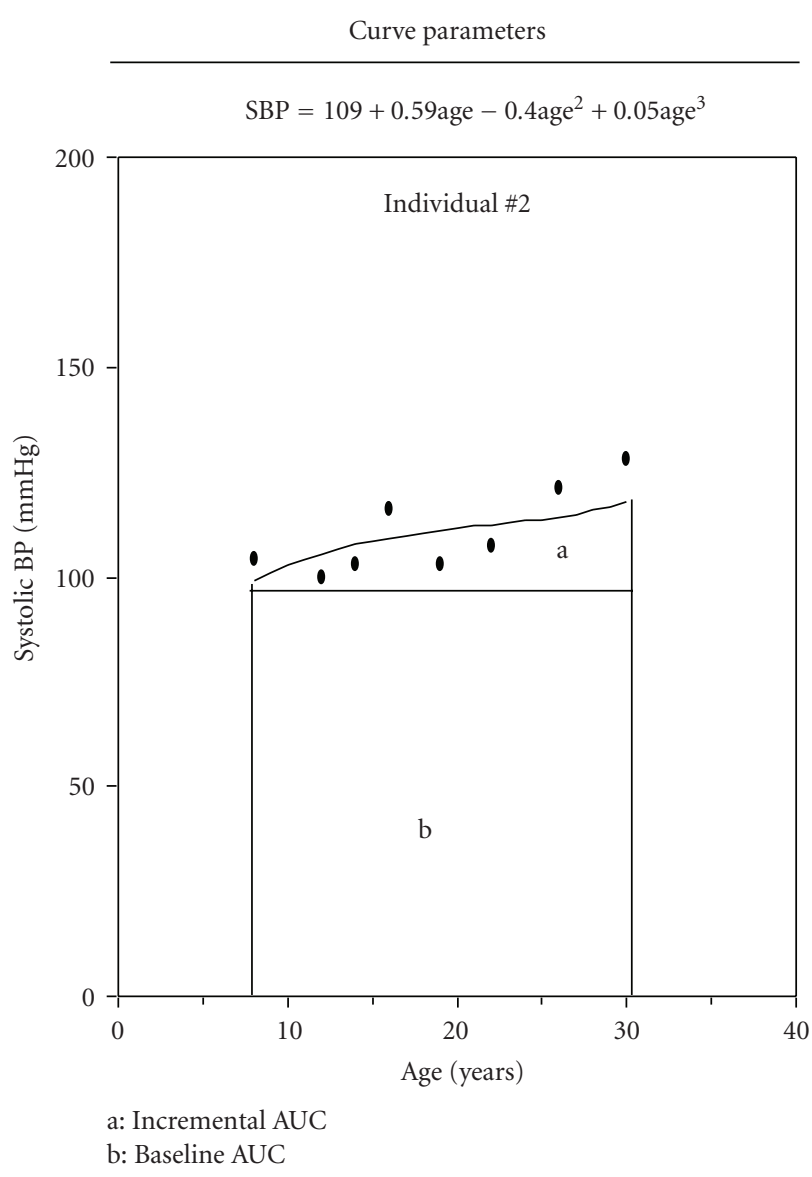

(b)

Figure 1: Illustration for Calculation of Area under the Curve of Systolic Blood Pressure: The Bogalusa Heart Study.

a significant race difference (blacks $>$ whites) among females only and a sex difference (males $>$ females) among whites only. Blacks had significantly lower birthweight than whites, but males had significantly higher birth weight than females only among whites.

Blacks displayed a lower alleles frequencies of $\beta_{2}$-AR Gly16 (0.507 versus $0.630, P<.001)$ and $\beta_{3}$-AR Trp64 (0.895 versus $0.925, P=.008)$ than whites. The genotype distributions were in accordance with Hardy-Weinberg equilibrium expectations in blacks and whites (data not shown).

Standardized regression coefficients for $\beta$-AR genotypes, race-adjusted birthweight, and covariates for race-adjusted BP are presented in two models in Table 2. Since racebirthweight and race-gene interactions on $\mathrm{BP}$ were not significant, the results of the total sample with blacks and whites combined are displayed. Race was not included in the models because birthweight and BP were adjusted for race by standardization prior to the regression analyses. The associations between race and Z-scores of BP measures (childhood, adulthood, AUC and age-related trend) were no longer significant $(P=.725-.896)$. In model I with current BMI included, childhood age and current BMI, but not birthweight, were associated with the first SBP measurement in childhood. Female sex, older age, higher adulthood BMI, and lower birthweight were significantly associated with higher values of the last SBP measurement in adulthood, total SBP AUC, and SBP age-related trend. Birthweight was significantly associated with adulthood DBP levels and agerelated trend; however, the association was weaker than for SBP. In addition, the first BP measurement in childhood (the baseline value) was also a significant predictor of the age-related trend of both SBP and DBP. In model II without current BMI included, the effect of birthweight on SBP was attenuated to some extent for adulthood SBP, SBP AUC, and the age-related trend, but they were still significant; the regression coefficients for other covariates did not considerably changed compared with those in model I. Birthweight was associated with the age-related trend only for DBP in model II. The main effect of individual $\beta 2$-AR and $\beta 3$-AR polymorphism genotype on SBP and DBP was not significant in both model I and model II without any interaction terms included.

Figure 2 illustrates the magnitude of the association of birthweight with SBP age-related trend, measured as standardized regression coefficients, by the combination of $\beta_{2}$ $\mathrm{AR}$ and $\beta_{3}$-AR genotypes. The regression coefficients of SBP age-related trend on birthweight were derived from multiple regression models using race-adjusted birthweight and $\mathrm{BP}$ 
TABLe 1: Mean Levels and SD of Study Variables by Race and Sex.

\begin{tabular}{|c|c|c|c|c|c|c|c|c|c|c|}
\hline & \multicolumn{4}{|c|}{ Whites } & \multicolumn{4}{|c|}{ Blacks } & & \\
\hline & \multicolumn{2}{|c|}{$\begin{array}{c}\text { Males } \\
(n=226)\end{array}$} & \multicolumn{2}{|c|}{$\begin{array}{l}\text { Females } \\
(n=289)\end{array}$} & \multicolumn{2}{|c|}{$\begin{array}{c}\text { Males } \\
(n=86)\end{array}$} & \multicolumn{2}{|c|}{$\begin{array}{l}\text { Females } \\
(n=138)\end{array}$} & \multicolumn{2}{|c|}{$P$-value for difference } \\
\hline & Mean & $\mathrm{SD}$ & Mean & $\mathrm{SD}$ & Mean & SD & Mean & $\mathrm{SD}$ & Race & Sex \\
\hline \multicolumn{11}{|l|}{ Childhood } \\
\hline Age (year) & 10.3 & 2.9 & 9.7 & 3.0 & 10.0 & 2.9 & 9.6 & 2.7 & NS & $<.05 \mathrm{w}$ \\
\hline Systolic BP (mm Hg) & 100.8 & 9.4 & 99.4 & 9.1 & 99.8 & 11.8 & 99.0 & 9.6 & NS & NS \\
\hline Diastolic BP (mm Hg) & 61.7 & 8.2 & 62.2 & 8.8 & 62.4 & 8.0 & 61.0 & 8.6 & NS & NS \\
\hline \multicolumn{11}{|l|}{ Adulthood } \\
\hline Age (year) & 37.6 & 5.1 & 36.7 & 5.5 & 35.0 & 5.9 & 35.9 & 5.7 & $<.01 \mathrm{~m}$ & NS \\
\hline Systolic BP (mm Hg) & 117.1 & 10.7 & 109.5 & 10.8 & 122.8 & 15.2 & 119.3 & 17.3 & $<.01$ & $<.05 \mathrm{w}$ \\
\hline Diastolic BP (mm Hg) & 78.9 & 8.0 & 73.8 & 7.9 & 81.2 & 11.8 & 78.7 & 11.5 & $<.05$ & $<.05$ \\
\hline \multicolumn{11}{|l|}{ AUC Values (mm Hg) } \\
\hline Systolic BP total & 113.1 & 7.2 & 106.9 & 5.5 & 115.0 & 7.6 & 110.7 & 6.8 & $<.05$ & $<.01$ \\
\hline Systolic BP trend & 11.8 & 5.1 & 7.5 & 5.3 & 15.6 & 6.6 & 11.8 & 6.2 & $<.01$ & $<.01$ \\
\hline Diastolic BP total & 72.3 & 5.8 & 69.7 & 4.5 & 72.3 & 6.2 & 70.8 & 5.0 & $<.01 \mathrm{f}$ & $<.05$ \\
\hline Diastolic BP trend & 10.8 & 3.3 & 8.1 & 4.0 & 10.8 & 3.8 & 9.7 & 4.2 & $<.01 \mathrm{f}$ & $<.01 \mathrm{w}$ \\
\hline \multicolumn{11}{|l|}{ At Birth } \\
\hline Gestational age (week) & 39.8 & 1.6 & 39.6 & 2.0 & 39.2 & 2.3 & 39.5 & 1.8 & $<.05 \mathrm{~m}$ & NS \\
\hline Birth weight (kg) & 3.46 & 0.5 & 3.34 & 0.6 & 3.09 & 0.6 & 3.00 & 0.6 & $<.01$ & $<.05 \mathrm{w}$ \\
\hline Birth weight $(\mathrm{kg})^{\dagger}$ & 3.44 & 0.5 & 3.33 & 0.5 & 3.10 & 0.5 & 3.00 & 0.5 & $<.01$ & $<.05 \mathrm{w}$ \\
\hline
\end{tabular}

BP: blood pressure; AUC: area under the curve.

NS : $P>.05$; $\mathrm{f}$ : females only; $\mathrm{m}$ : males only; $\mathrm{w}$ : whites only.

$\dagger$ adjusted for gestational age.

TABle 2: Standardized regression coefficients of race-adjusted blood pressure on birth weight, $\beta$-adrenergic receptor genotypes, and covariates.

\begin{tabular}{|c|c|c|c|c|c|c|c|c|}
\hline & \multicolumn{4}{|c|}{ Systolic BP } & \multicolumn{4}{|c|}{ Diastolic BP } \\
\hline & First & Last & AUC & Trend & First & Last & AUC & Trend \\
\hline \multicolumn{9}{|l|}{ Model I } \\
\hline Childhood BP & - & - & - & $-0.43^{* *}$ & - & - & - & $-0.44^{* *}$ \\
\hline Female sex & -0.05 & $-0.24^{* *}$ & $-0.37^{* *}$ & $-0.38^{* *}$ & 0.02 & $-0.22 * *$ & $-0.19^{* *}$ & $-0.28^{* *}$ \\
\hline Age & $0.22 * *$ & $0.19^{* *}$ & $0.17^{* *}$ & $-0.20^{* *}$ & $0.28^{* *}$ & $0.25^{* *}$ & $0.34^{* *}$ & -0.02 \\
\hline BMI & $0.16^{* *}$ & $0.36^{* *}$ & $0.26^{* *}$ & $0.23 * *$ & 0.06 & $0.34^{* *}$ & $0.21^{* *}$ & $0.26^{* *}$ \\
\hline Birth weight ${ }^{\dagger}$ & -0.004 & $-0.11^{* *}$ & $-0.11^{* *}$ & $-0.10^{* *}$ & 0.04 & $-0.07^{*}$ & $-0.07^{*}$ & $-0.08^{*}$ \\
\hline$\beta_{2}$-AR genotype & -0.04 & -0.03 & -0.04 & 0.01 & -0.05 & -0.02 & -0.03 & -0.01 \\
\hline$\beta_{3}$-AR genotype & -0.04 & -0.01 & -0.02 & 0.02 & -0.05 & -0.01 & -0.05 & -0.01 \\
\hline \multicolumn{9}{|l|}{ Model II } \\
\hline Childhood BP & - & - & - & $-0.40^{* *}$ & - & - & - & $-0.42^{* *}$ \\
\hline Female sex & -0.05 & $-0.25^{* *}$ & $-0.38^{* *}$ & $-0.39 * *$ & 0.01 & $-0.24^{* *}$ & $-0.20^{* *}$ & $-0.29 * *$ \\
\hline Age & $0.23^{* *}$ & $0.22 * *$ & $0.19^{* *}$ & $-0.19^{* *}$ & $0.28^{* *}$ & $0.28^{* *}$ & $0.36^{* *}$ & -0.01 \\
\hline Birth weight ${ }^{\dagger}$ & -0.004 & $-0.09^{* *}$ & $-0.10^{* *}$ & $-0.09^{* *}$ & 0.04 & -0.05 & -0.06 & $-0.07^{*}$ \\
\hline$\beta_{2}$-AR genotype & -0.05 & -0.05 & -0.05 & -0.02 & -0.05 & -0.04 & -0.04 & -0.02 \\
\hline$\beta_{3}-\mathrm{AR}$ genotype & -0.04 & -0.01 & -0.02 & 0.02 & -0.05 & -0.01 & -0.05 & -0.01 \\
\hline
\end{tabular}

First: the first measurement in childhood; last: the last measurement in adulthood; BP: blood pressure;

AUC: area under the curve; BMI: body mass index.

$\beta_{2}$-AR genotype $=\beta_{2}$-adrenergic receptor Arg16Gly (coding: 0, 1, and 2 of Arg alleles).

$\beta_{3}$-AR genotype $=\beta_{3}$ - adrenergic receptor Trp64Arg (coding: $0=\operatorname{Arg} / \operatorname{Arg}$ and $\operatorname{Trp} / \operatorname{Arg}, 1=\operatorname{Trp} / \operatorname{Trp}$ ).

${ }^{\dagger}$ adjusted for gestational age.

${ }^{*} P<.05 ;{ }^{* *} P<.01$. 




Figure 2: Relationship between Age-related Trend of Systolic Blood Pressure and Birth Weight by $\beta_{2}$-AR Arg16Gly and $\beta_{3}$-AR Trp64Arg Genotypes: The Bogalusa Heart Study Arg/x stands for Arg/Trp and Arg/Arg genotypes combined.

in terms of race-specific Z-scores, adjusting for the first SBP measurement in childhood, adulthood age, and sex, without any interaction terms. Because the regression coefficients were all negative, standardized regression coefficients $\times(-1)$ were presented in Figure 2 for convenience. The regression coefficients showed opposite trends with increasing number of the $\beta_{2}$-AR Arg 16 alleles in the two $\beta_{3}$-AR genotype groups. The birthweight effect on SBP trend $(\beta=-0.12, P=.014$, $n=224)$ was the greatest among individuals who had $\beta_{3}$ AR Trp/Trp and $\beta_{2}$-AR Gly/Gly genotypes; having $\beta_{3}$-AR $\operatorname{Arg} / \mathrm{x}$ and $\beta_{2}$-AR Arg/Arg genotypes was associated with the highest effect of $\beta=-0.28(P=.257, n=21)$. The overall 3way interaction (birthweight- $\beta_{2}-\mathrm{AR}-\beta_{3}-\mathrm{AR}$ ) was significant $(\mathrm{P}=.042)$, suggesting that the relationship between SBP agerelated trend and birthweight depends on the combination of $\beta_{2}-\mathrm{AR}$ and $\beta_{3}-\mathrm{AR}$ genotypes. Further, the interaction of individual polymorphisms with birthweight on SBP trend was not significant in the 2-way interaction models without a 3-way interaction term included (data not shown).

Figure 3 presents the strength of the association of birthweight with SBP age-related trend by the combination of $\beta_{2}-\mathrm{AR}$ and $\beta_{3}$-AR genotypes in blacks and whites using the race-specific Z-scores of birthweight and SBP age-related trend. The pattern of the standardized regression coefficients of SBP age-related trend on birthweight by $\beta_{2}$-AR and $\beta_{3}$ AR genotypes was similar in the two race groups; the fourway interaction (race-birthweight- $\beta_{2}-\mathrm{AR}-\beta_{3}-\mathrm{AR}$ ) was not significant $(P=.523)$.

For DBP age-related trend, a similar pattern of regression coefficients to SBP was observed with respect to $\beta_{2}-\mathrm{AR}$ and $\beta_{3}$-AR genotypes; the birthweight- $\beta_{2}$-AR- $\beta_{3}$-AR interaction on DBP age-related trend was significant $(P=.039)$ in the total sample. Blacks and whites did not show any difference in the birthweight-genotype interaction on DBP age-related trend $(P=.682)$.

\section{Discussion}

Many studies have shown that low birthweight is inversely associated with high BP and hypertension in later life [1-4]

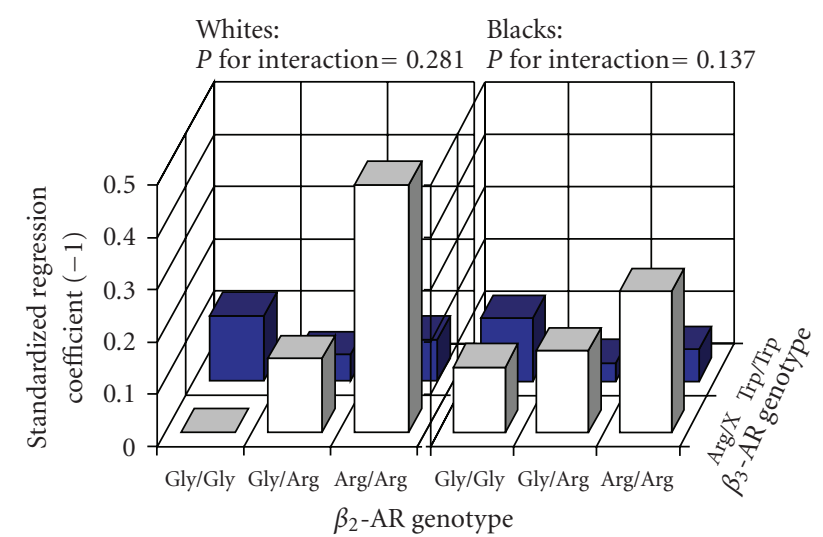

FIgURE 3: Relationship between Age-related Trend of Systolic Blood Pressure and Birth Weight by $\beta_{2}$-AR Arg16Gly and $\beta_{3}$-AR Trp64Arg Genotypes in Blacks and Whites: The Bogalusa Heart Study Arg/x stands for Arg/Trp and Arg/Arg genotypes combined.

although there exist criticisms and concerns [3, 8-12]. Systematic reviews of the literature suggest an inverse linear relationship between SBP and birthweight of $\sim 1-2 \mathrm{~mm} \mathrm{Hg} / \mathrm{kg}$ [29]. However, most previous studies in this regard focused on BP levels; limited information is available on the influence of birthweight on longitudinal changes of BP. The present community-based study demonstrates an adverse effect of low birthweight on BP in terms of adulthood BP, the longterm levels, and increasing trend from childhood to young adulthood, especially for SBP. However, the birthweight-BP association was not noted in childhood in the study cohort.

The hypothesis of the fetal origins of hypertension proposed several possible mechanisms linking reduced fetal growth and elevated BP in later life, such as persisting changes in vascular structure, including loss of elasticity in vessel walls, effects of glucocorticoid hormones, and abnormalities of nephrogenesis [1,2]. Furthermore, low birthweight may be associated with elevated sympathetic nervous system activity in adulthood, as measured by heart rate, preejection period, and respiratory sinus arrhythmia $[30,31]$. These findings suggest that increased sympathetic nervous system activity established in utero may be one of the mechanisms linking low birthweight with high BP in adults. Although genetic factors have been found to play a role in the birthweight-BP relationship in family and twin studies [31-33], limited information on specific genes has become available. We noted in the current study that the association between birthweight and age-related trend of $\mathrm{BP}$ was dependent on the combination of by $\beta_{2}-\mathrm{AR}$ and $\beta_{3}-\mathrm{AR}$ genotypes, suggesting that $\beta$-AR gene variants play a role, in an interactive manner, in BP regulation of adults who have a low birthweight, an indicator of fetal growth restriction.

It is well established that both BP regulation and birthweight are genetically determined $[34,35]$. Candidate genes and chromosomal regions have been identified for birthweight $[36,37]$. $\beta$-ARs are an important component of the sympathetic nervous system [13, 14]. Polymorphisms of the $\beta$-AR genes have been found to be associated with 
multiple cardiovascular risk factors, including hemodynamic status and obesity measures. Previous studies have shown that $\beta_{2}$-AR Gly16 and $\beta_{3}$-AR Arg64 alleles were associated with BP elevation or hypertension, although the findings on $\beta_{2}$-AR Gly16 allele have been questioned $[16,38]$. In the present study, we did not find a significant association of $\beta_{2}$-AR Arg16Gly and $\beta_{3}$-AR Trp64Arg polymorphisms, individually, with BP in terms of childhood, adulthood, and long-term BP levels, and the age-related trend. However, the two genes were found to interactively influence the relationship of birthweight to longitudinal changes of BP. Individuals who were born a lower weight and have $\beta_{2}$-AR Arg/Arg and $\beta_{3}$-AR Arg allele or $\beta_{2}$-AR Gly/Gly and $\beta_{3}$ AR Trp/Trp genotypes are prone to have a faster increase in BP after birth compared with those having a normal birthweight and other $\beta_{2}$-AR and $\beta_{3}$-AR genotypes. Data on 3 -way interaction (birthweight- $\beta_{2}-\mathrm{AR}-\beta_{3}-\mathrm{AR}$ ) on $\mathrm{BP}$, which is a complex interplay, have not been previously reported. Further studies with multiple polymorphisms of the two genes are needed to confirm the findings in this study with respect to the possible important loci which are in linkage disequilibrium with $\beta_{2}$-AR Arg16Gly and $\beta_{3}$-AR Trp64Arg polymorphisms.

In the United States, blacks have a greater prevalence of both low birthweight and hypertension than whites; however, it is not yet established that excess risk of hypertension in blacks is programmed in utero [39]. In some studies black children showed a weaker birthweight-BP association than white children, or none at all [40-43]. A weaker birthweight-BP association in blacks was also observed in our previous study in a separate cohort [44]. However, the modulating effect of $\beta_{2}$-AR and $\beta_{3}$-AR genes, individually or in combination, on the association between birthweight and longitudinal changes of BP did not differ between blacks and whites in the present study. In addition to race differences in brithweight and $\mathrm{BP}, \beta_{2}$-AR and $\beta_{3}$-AR genes allele frequencies also differed significantly between blacks and whites in this study cohort. Strong correlations among these study variables would lead to a serious bias resulted from population stratification when blacks and whites were combined for analysis. For this reason, BP and birthweight were standardized by race groups, and then race-specific Zscores were used in association and interaction analyses in the present study.

It is well known that size at birth is strongly related to fetal genotype, uterine environment, and a number of maternal factors including parity, length of gestation, mother's adult size, mother's own birthweight, as well as mother's genotype $[34,45]$. Because of the correlation of maternal and fetal genotypes of multiple relevant genes, maternal genotypes are expected to have a confounding effect on the birthweight-BP relationship as well as its genetic modulation by $\beta_{2}-\mathrm{AR}$ and $\beta_{3}$-AR gene polymorphisms noted in this study. However, mother's genotype data are not available in our cohort. Another limitation of this community-based study is that only one single polymorphism was typed in each of the two genes under study.

In summary, we found in the current study that low birth weight was associated with a greater increase in BP levels from childhood to adulthood. This relationship was modulated by the combination of $\beta 2$-AR and $\beta 3$-AR genotypes. These findings support the emerging concept of intrauterine programming and its pathophysiologic consequences after birth and underscore the role of genetic factors in the fetal origins of hypertension later in life. Since no data in this regard are available for comparison, our findings need to be replicated in other populations.

\section{Acknowledgments}

The authors appreciate the continued role of participants in the Bogalusa Heart Study and thank Dr. Eric Boerwinkle for performing genotyping for the present study. they also express appreciation for support given by the Louisiana Office of Public Health. This study was supported by Grants 0855082E from the American Heart Association, HD-061437 from the National Institute of Child Health and Human Development, HL-70568 from the National Heart, Lung, Blood Institute, and AG-16592 from the National Institute on Aging.

\section{References}

[1] A. M. Nuyt and B. T. Alexander, "Developmental programming and hypertension," Current Opinion in Nephrology and Hypertension, vol. 18, no. 2, pp. 144-152, 2009.

[2] D. S. Gardner, R. C. Bell, and M. E. Symonds, "Fetal mechanisms that lead to later hypertension," Current Drug Targets, vol. 8, no. 8, pp. 894-905, 2007.

[3] K. S. Joseph and M. S. Kramer, "Review of the evidence on fetal and early childhood antecedents of adult chronic disease," Epidemiologic Reviews, vol. 18, no. 2, pp. 158-174, 1996.

[4] D. J. P. Barker, C. Osmond, J. Golding, D. Kuh, and M. E. J. Wadsworth, "Growth in utero, blood pressure in childhood and adult life, and mortality from cardiovascular disease," British Medical Journal, vol. 298, no. 6673, pp. 564-567, 1989.

[5] A. Lucas and R. Morley, "Does early nutrition in infants born before term programme later blood pressure?" British Medical Journal, vol. 309, no. 6950, pp. 304-308, 1994.

[6] C. S. Uiterwaal, S. Anthony, L. J. Launer, et al., "Birth weight, growth, and blood pressure: an annual follow-up study of children aged 5 through 21 years," Hypertension, vol. 30, no. 2, pp. 267-271, 1997.

[7] P. H. Whincup, M. Bredow, F. Payne, S. Sadler, and J. Golding, "Size at birth and blood pressure at 3 years of age: the Avon Longitudinal Study of Pregnancy and Childhood (ALSPAC)," American Journal of Epidemiology, vol. 149, no. 8, pp. 730-739, 1999.

[8] Y.-K. Tu, R. West, G. T. H. Ellison, and M. S. Gilthorpe, "Why evidence for the fetal origins of adult disease might be a statistical artifact: the "reversal paradox" for the relation between birth weight and blood pressure in later life," American Journal of Epidemiology, vol. 161, no. 1, pp. 27-32, 2005.

[9] Y.-K. Tu, M. S. Gilthorpe, and G. T. H. Ellison, "What is the effect of adjusting for more than one measure of current body size on the relation between birthweight and blood pressure?" Journal of Human Hypertension, vol. 20, no. 9, pp. 646-657, 2006. 
[10] N. Paneth, F. Ahmed, and A. D. Stein, "Early nutritional origins of hypertension: a hypothesis still lacking support," Journal of Hypertension, Supplement, vol. 14, no. 5, pp. S121S129, 1996.

[11] A. Lucas, M. S. Fewtrell, and T. J. Cole, "Fetal origins of adult disease-the hypothesis revisited," British Medical Journal, vol. 319, no. 7204, pp. 245-249, 1999.

[12] R. Huxley, A. Neil, and R. Collins, "Unravelling the fetal origins hypothesis: is there really an inverse association between birthweight and subsequent blood pressure?" The Lancet, vol. 360, no. 9334, pp. 659-665, 2002.

[13] H. Zhu, J. Poole, Y. Lu, et al., "Sympathetic nervous system, genes and human essential hypertension," Current Neurovascular Research, vol. 2, no. 4, pp. 303-317, 2005.

[14] N. Dzimiri, "Receptor crosstalk. Implications for cardiovascular function, disease and therapy," European Journal of Biochemistry, vol. 269, no. 19, pp. 4713-4730, 2002.

[15] S. B. Liggett, "Polymorphisms of adrenergic receptors: variations on a theme," Assay and Drug Development Technologies, vol. 1, no. 2, pp. 317-326, 2003.

[16] O.-E. Brodde, " $\beta-1$ and $\beta-2$ adrenoceptor polymorphisms: functional importance, impact on cardiovascular diseases and drug responses," Pharmacology and Therapeutics, vol. 117, no. 1, pp. 1-29, 2008.

[17] K. Doh, I. Sziller, S. Vardhana, E. Kovacs, Z. Papp, and S. S. Witkin, " $\beta 2$-adrenergic receptor gene polymorphisms and pregnancy outcome," Journal of Perinatal Medicine, vol. 32, no. 5, pp. 413-417, 2004.

[18] K. S. Crider, N. Whitehead, and R. M. Buus, "Genetic variation associated with preterm birth: a HuGE review," Genetics in Medicine, vol. 7, no. 9, pp. 593-604, 2005.

[19] X. Wang, Y. Cui, X. Tong, H. Ye, and S. Li, "Effects of the Trp64Arg polymorphism in the $\beta 3$-adrenergic receptor gene on insulin sensitivity in small for gestational age neonates," Journal of Clinical Endocrinology and Metabolism, vol. 89, no. 10, pp. 4981-4985, 2004.

[20] D. Jaquet, D. A. Tregouet, T. Godefroy, et al., "Combined effects of genetic and environmental factors on insulin resistance associated with reduced fetal growth," Diabetes, vol. 51, no. 12, pp. 3473-3478, 2002.

[21] "The Bogalusa heart study 20th anniversary symposium," The American Journal of the Medical Sciences, vol. 310, pp. S1-S138, 1995.

[22] G. S. Berenson, C. A. McMahan, A. W. Voors, et al., Cardiovascular Risk Factors in Children-The Early Natural History of Atherosclerosis and Essential Hypertension, C. Andrews and H. E. Hester, Ed., Oxford University Press, New York, NY, USA, 1980.

[23] J. Cui, J. L. Hopper, and S. B. Harrap, "Genes and family environment explain correlations between blood pressure and body mass index," Hypertension, vol. 40, no. 1, pp. 7-12, 2002.

[24] J. D. Neaton, R. H. Grimm Jr., R. J. Prineas, et al., "Treatment of mild hypertension study: final results," Journal of the American Medical Association, vol. 270, no. 6, pp. 713-724, 1993.

[25] D. L. Ellsworth, S. A. Coady, W. Chen, et al., "Influence of the $\beta 2$-adrenergic receptor Arg16Gly polymorphism on longitudinal changes in obesity from childhood through young adulthood in a biracial cohort: the Bogalusa heart study," International Journal of Obesity, vol. 26, no. 7, pp. 928937, 2002.
[26] D. L. Ellsworth, S. A. Coady, W. Chen, S. R. Srinivasan, E. Boerwinkle, and G. S. Berenson, "Interactive effects between polymorphisms in the $\beta$-adrenergic receptors and longitudinal changes in obesity," Obesity Research, vol. 13, no. 3, pp. 519-526, 2005.

[27] W. Chen, S. Li, S. R. Srinivasan, E. Boerwinkle, and G. S. Berenson, "Autosomal genome scan for loci linked to blood pressure levels and trends since childhood: the Bogalusa heart study," Hypertension, vol. 45, no. 5, pp. 954-959, 2005.

[28] N. R. Cook, B. A. Rosner, W. Chen, S. R. Srinivasan, and G. S. Berenson, "Using the area under the curve to reduce measurement error in predicting young adult blood pressure from childhood measures," Statistics in Medicine, vol. 23, no. 22, pp. 3421-3435, 2004.

[29] C. M. Law and A. W. Shiell, "Is blood pressure inversely related to birth weight? The strength of evidence from a systematic review of the literature," Journal of Hypertension, vol. 14, no. 8, pp. 935-941, 1996.

[30] D. I. W. Phillips and D. J. P. Barker, "Association between low birthweight and high resting pulse in adult life: is the sympathetic nervous system involved in programming the insulin resistance syndrome?" Diabetic Medicine, vol. 14, no. 8, pp. 673-677, 1997.

[31] R. G. IJzerman, C. D. A. Stehouwer, E. J. de Geus, M. M. van Weissenbruch, H. A. Delemarre-van de Waal, and D. I. Boomsma, "Low birth weight is associated with increased sympathetic Activity: dependence on genetic factors," Circulation, vol. 108, no. 5, pp. 566-571, 2003.

[32] R. G. IJzerman, C. D. A. Stehouwer, and D. I. Boomsma, "Evidence for genetic factors explaining the birth weightblood pressure relation: analysis in twins," Hypertension, vol. 36, no. 6, pp. 1008-1012, 2000.

[33] D. A. Leon, I. Koupil, V. Mann, et al., "Fetal, developmental, and parental influences on childhood systolic blood pressure in 600 sib pairs: the Uppsala family study," Circulation, vol. 112, no. 22, pp. 3478-3485, 2005.

[34] A. La Batide-Alanore, D.-A. Trégouët, D. Jaquet, J. Bouyer, and L. Tiret, "Familial aggregation of fetal growth restriction in a French cohort of 7,822 term births between 1971 and 1985," American Journal of Epidemiology, vol. 156, no. 2, pp. 180-187, 2002.

[35] F. C. Luft, "Molecular genetics of human hypertension," Journal of Hypertension, vol. 16, pp. 1871-1878, 1998.

[36] J. Pihlajamaki, M. Vanhala, P. Vanhala, and M. Laakso, "The Pro12Ala polymorphism of the PPAR $\gamma 2$ gene regulates weight from birth to adulthood," Obesity Research, vol. 12, no. 2, pp. 187-190, 2004.

[37] R. Arya, E. Demerath, C. P. Jenkinson, et al., "A quantitative trait locus (QTL) on chromosome 6q influences birth weight in two independent family studies," Human Molecular Genetics, vol. 15, no. 10, pp. 1569-1579, 2006.

[38] H. Kawaguchi, K. Masuo, T. Katsuya, et al., “ $\beta 2$ - and $\beta 3$ adrenoceptor polymorphisms relate to subsequent weight gain and blood pressure elevation in obese normotensive individuals," Hypertension Research, vol. 29, no. 12, pp. 951959, 2006.

[39] T. Forrester, "Historic and early life origins of hypertension in Africans," Journal of Nutrition, vol. 134, no. 1, pp. 211-216, 2004.

[40] S. G. Rostand, S. P. Cliver, and R. L. Goldenberg, "Racial disparities in the association of foetal growth retardation to childhood blood pressure," Nephrology Dialysis Transplantation, vol. 20, no. 8, pp. 1592-1597, 2005. 
[41] C. M. Law, P. Egger, O. Dada, et al., "Body size at birth and blood pressure among children in developing countries," International Journal of Epidemiology, vol. 30, no. 1, pp. 52-57, 2001.

[42] B. Falkner, S. Hulman, and H. Kushner, "Effect of birth weight on blood pressure and body size in early adolescence," Hypertension, vol. 43, no. 2, pp. 203-207, 2004.

[43] S. Hulman, H. Kushner, S. Katz, and B. Falkner, "Can cardiovascular risk be predicted by newborn, childhood, and adolescent body size? An examination of longitudinal data in urban African Americans," Journal of Pediatrics, vol. 132, no. 1, pp. 90-97, 1998.

[44] F. Mzayek, R. Sherwin, V. Fonseca, et al., "Differential association of birth weight with cardiovascular risk variables in African- Americans and Whites: the Bogalusa heart study," Annals of Epidemiology, vol. 14, no. 4, pp. 258-264, 2004.

[45] D. B. Dunger, C. J. Petry, and K. K. Ong, "Genetics of size at birth," Diabetes Care, vol. 30, supplement 2, pp. S150-S155, 2007. 

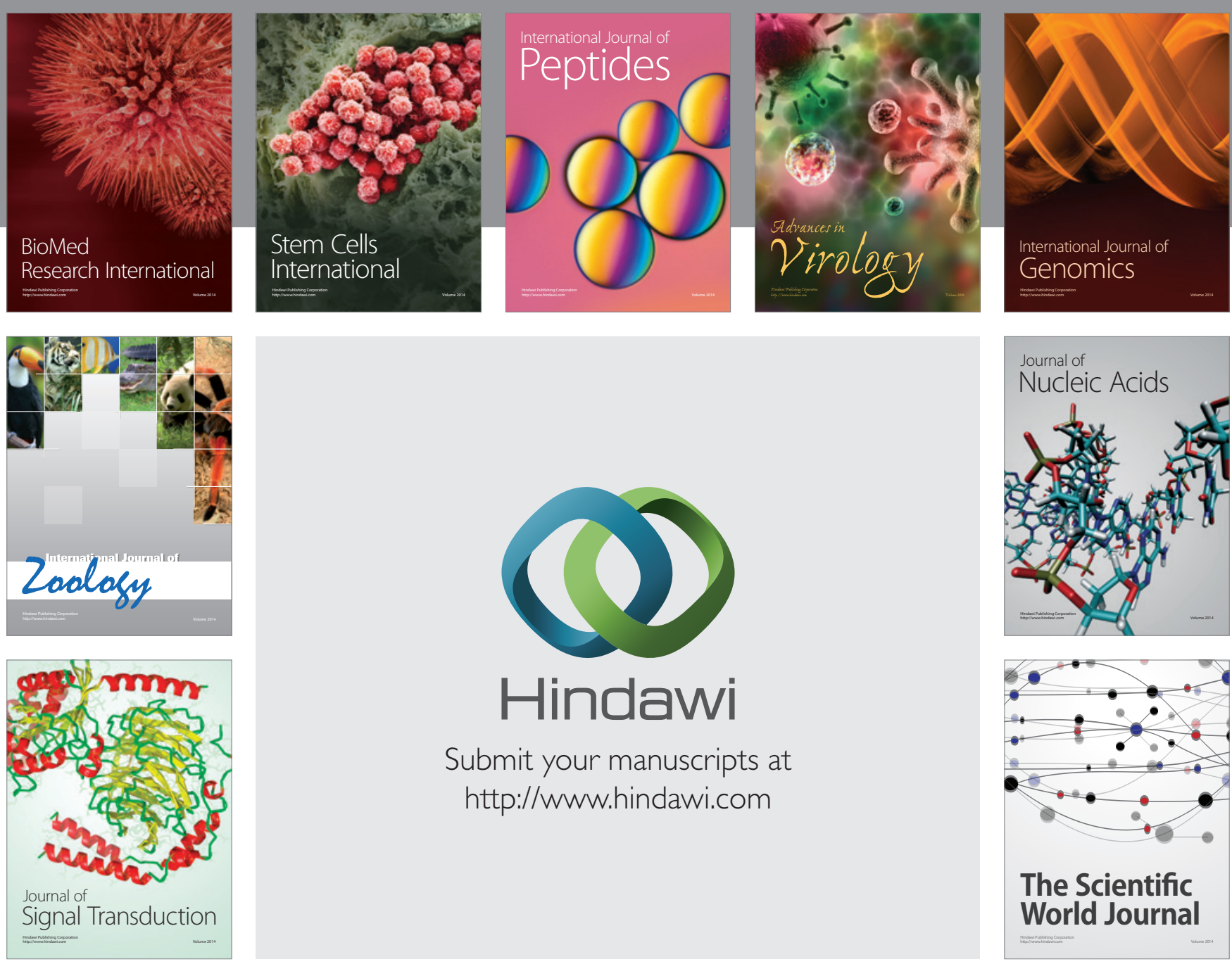

Submit your manuscripts at

http://www.hindawi.com
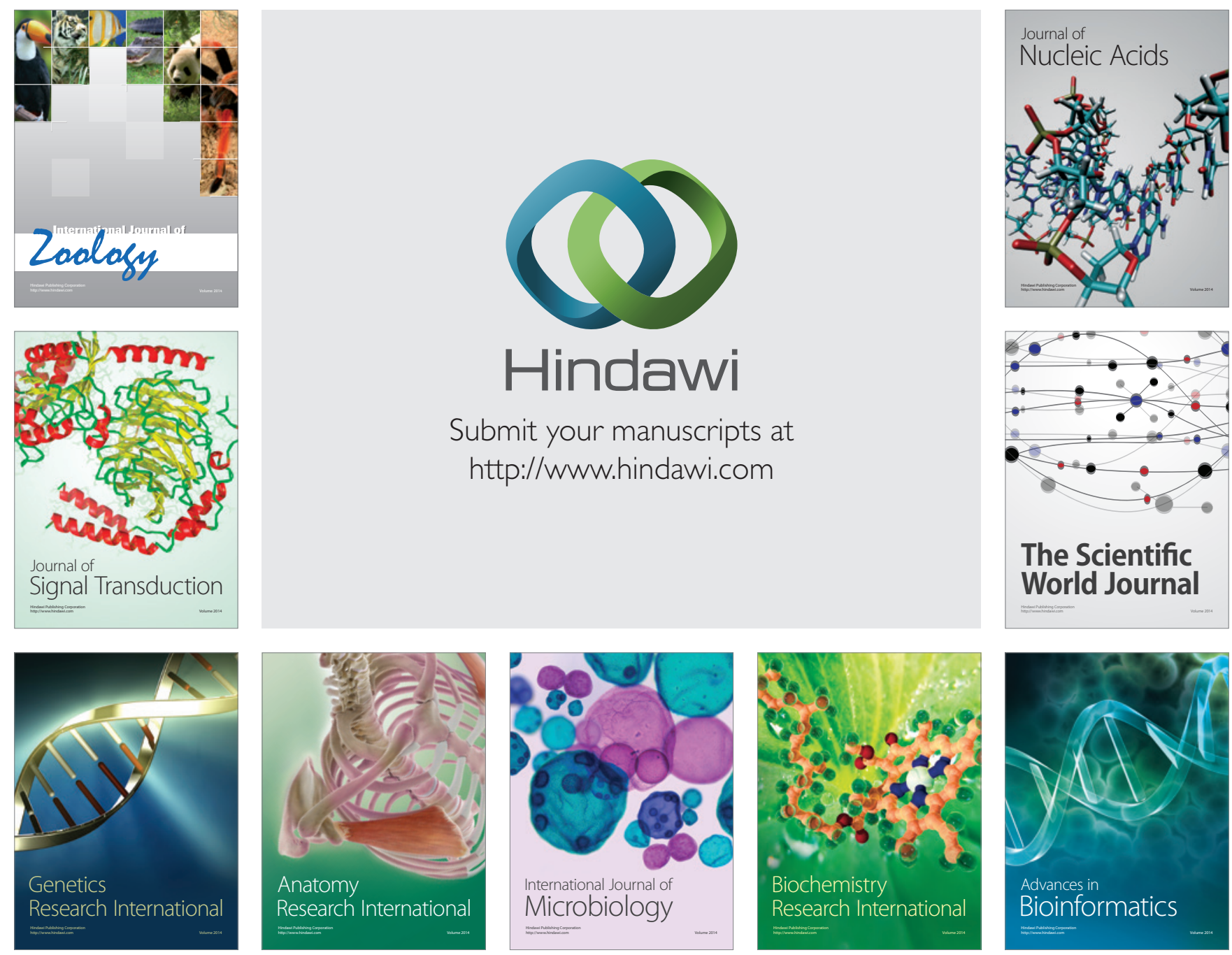

The Scientific World Journal
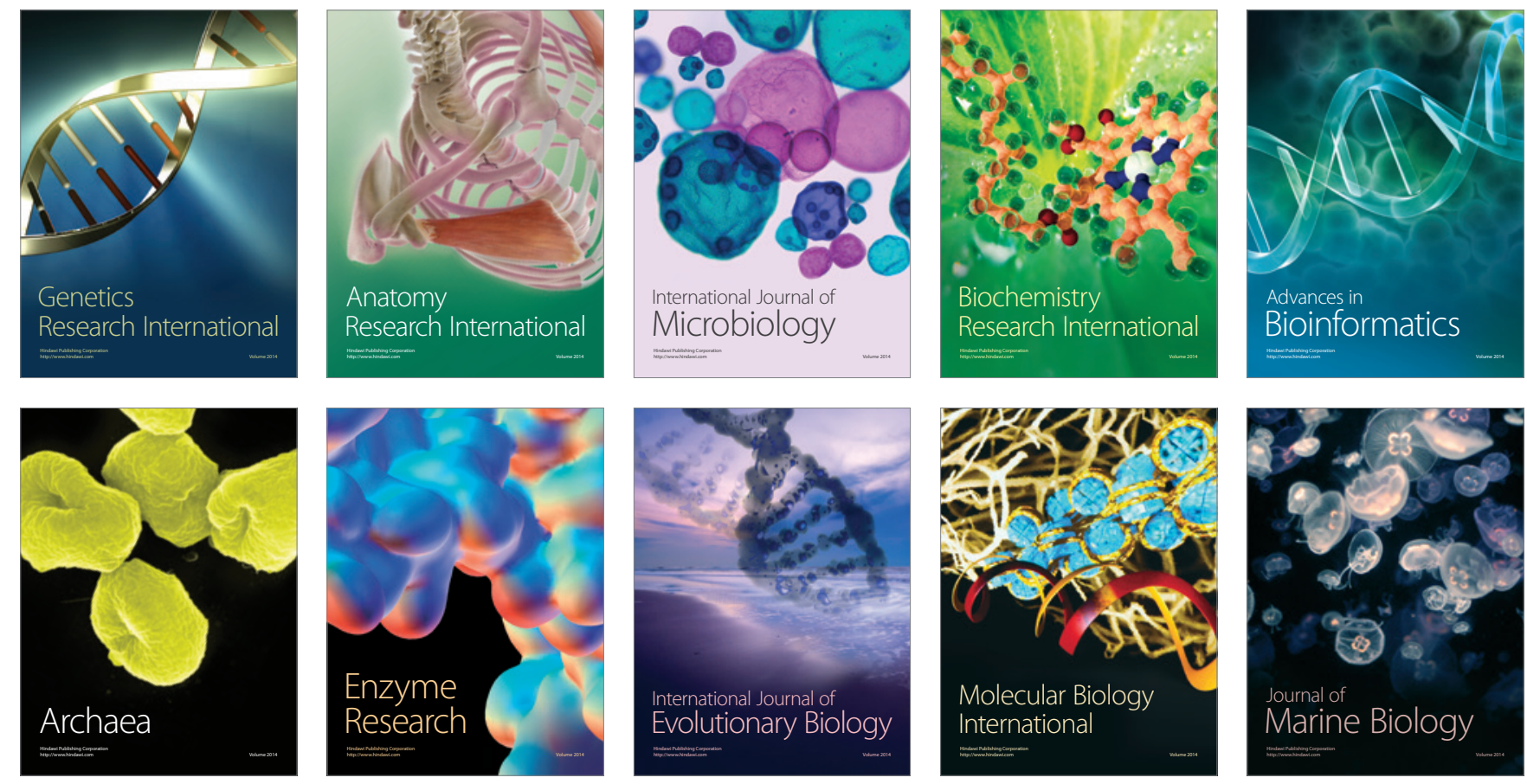